\title{
Grid connected photovoltaic system efficiency and quality improvement using fuzzy-InCond MPPT
}

\author{
Amara Yasmine', Bradai Rafik ${ }^{2}$, Boukenoui Rachid ${ }^{3}$, Mellit Adel ${ }^{4}$ \\ ${ }^{1}$ Set Laboratory, Electronics Department, Blida 1 University, Algeria \\ ${ }^{2}$ LATSILaboratory, Electronics Department, Blida1University, Algeria \\ ${ }^{3}$ Renewable Energies department, Faculty of Technology, Blida 1 University, Algeria \\ ${ }^{4}$ Renewable Energy Laboratory, Jijel University, Algeria
}

\section{Article Info}

Article history:

Received Jan 5, 2020

Revised Apr 3, 2020

Accepted Apr 23, 2020

Keywords:

Efficiency

FL

Grid connected

InCond

MPPT

Photovoltaic system

Quality

ABSTRACT

Maximum Power Point Tracking (MPPT) techniques are developed to harvest and supply maximum power to the load. This depends on the power generated and the MPPT accuracy. Under quick-changing weather conditions, Incremental Conductance (InCond) and numerous different algorithms may fail to track the exact Maximum Power Point (MPP) which may result in significant power loss. Fuzzy Logic (FL) based MPPT is quick and accurate in tracking the MPP, but the high complexity and the implementation difficulty are their main disadvantages. A novel FL-InCond MPPT improved technique is developed based on the features of InCond and FL techniques to overcome their drawbacks. The newly developed approach can automatically adjust the variation of the duty cycle for tracking the MPP with accuracy. The obtained results are compared with conventional Perturb and observe (P\&O) and InCond MPPTs for grid-connected mode under fast weather conditions. It is demonstrated that the developed method outperforms the aforementioned MPPT techniques in terms of tracking response, efficiency and the delivered current quality.
\end{abstract}

This is an open access article under the CC BY-SA license.

\section{Corresponding Author:}

Amara Yasmine,

Set Laboratory, Electronics Department,

Blida 1 University,

09000 Blida, Algeria.

Email: amara-yasmine@outlook.fr

\section{INTRODUCTION}

Renewable energy plays a significant role in the actual electricity production due to their environment-friendly features and the absence of $\mathrm{CO} 2$ emission. In fact, there are six widely known renewable energy sources which are solar, wind, hydraulic, biomass, geothermal and marine. Nevertheless, the most widely explored are wind and solar energy due to their abundance in large geographical areas on earth and they are coming closer to being competitive with existing fossil fuel and nuclear power generation [1]. Large scale installations of DC micro-grid using solar energy have been realized in the last few years [2]. Thanks to a physical and chemical phenomenon called the Photovoltaic (PV) effect, each solar cell produces voltage and electric current in its semiconductor material (e.g., silicon or germanium) upon exposure to light [3]. The produced voltage and current ( $\mathrm{I}_{\mathrm{PV}}$ and $\mathrm{V}_{\mathrm{PV}}$, respectively) have non-linear characteristics. Besides, they are strongly influenced by the temperature and irradiance. The existing DC-DC converters (Buck, Boost, Buck-boost, Cuk and Single-Ended Primary Inductor Converter (SEPIC) and Zeta) 
are used to adapt the PVG voltage to the load. To feed AC-loads and transfer the power to the distributed electrical grid a DC-AC inverter (single-phase, three-phase or multilevel) are essential.

To harvest the maximum available power from the PVG, a good choice of MPPT algorithm to control the electronic switch of the DC-DC converter is necessary[4]. The DC-DC converter and its MPPT controller act as a matching impedance unit between PVG and dc-load. Nominal duty cycle of the converter switch is adjusted by the MPPT controller to an optimum value, so the converter's input resistance is equal to the solar panel's equivalent output resistance. This ensures maximum power transfer [5]. Many MPPT algorithms have been studied and developed in the literature; they can be evaluated according to many performance indices such as the number of the used sensors, response time, complexity, dependence on the PV system parameters, the technique of implementation and cost [6]. MPPT algorithms are classified into two main categories: direct methods that do not require knowledge of the PVG parameters such as Perturb and Observe (P\&O), Hill-Climbing (HC), Incremental Conductance (InCond), Fuzzy Logic (FL) and Neural networks. However, indirect methods depend on the PVG parameters and need to isolate the PVG periodically to measure the variations of its parameters such as fractional open-circuit voltage, fractional short circuit current, fixed voltage, and current methods. It is worth mentioning that direct MPPT methods are widely explored and adapted as reviewed in $[6,7]$.

$\mathrm{P} \& \mathrm{O}, \mathrm{HC}$, and InCond methods are mainly adopted in many research papers due to their algorithm's simplicity, which can be easily implemented, as well as their high efficiency compared to the aforementioned indirect MPPT techniques. The principle of the $\mathrm{P} \& \mathrm{O}$ is based on measuring the voltage and current of the PVG iteratively, to calculate the instantaneous PV power. If the new calculated power value is greater than the previous one, the voltage is perturbed positively and the new power value will be recorded for the new iteration. Otherwise, the voltage should be decremented and the old power value will be kept. The operation continues until the instantaneous power reaches the MPP $[8,9]$. $\mathrm{P} \& \mathrm{O}$ and $\mathrm{HC}$ have the same fundamental principle. Their main difference lies in the strategy employed for controlling the electronic switch of the DC-DC converter. Hence, P\&O generates the appropriate duty cycle by means of a Proportional Integral (PI) controller, whereas, $\mathrm{HC}$ controls the DC-DC converter by involving a direct perturbation on the duty cycle. It should be mentioned that the direct duty cycle control strategy used by $\mathrm{HC}$ has the benefit of avoiding a PI controller and the trial-error approach for tuning its gains (Kp and $\mathrm{Ki})$.

The author in[10]tested P\&O, HC, InCond and FL Controller (FLC) under different levels of irradiance to compare their measured power waveforms. FL MPPT demonstrates a fast response time compared to the other investigated MPPTs. However, the algorithm's complexity of P\&O, HC and InCond are lower. In InCond MPPT, the conductance and the incremental conductance are calculated by the measured PV current and voltage. Then, their values are compared to make the right decision for incrementing or decrementing the voltage reference. The main objective of InCond MPPT is to achieve the optimal condition of MPP at which the instantaneous conductance is equal to the incremental conductance [11]. It is important to point out that in $\mathrm{P} \& \mathrm{O}, \mathrm{HC}$ and InCond MPPTs, using small perturbation step size increases the steady state tracking accuracy. However, the algorithm may fail to achieve the exact MPP under fast transient variations of irradiance. On the contrary, using large perturbation leads to considerable power ripples in steady-state conditions, reducing the tracking efficiency and affecting the stability of PV systems. The author in [12] proposed a variable step size InCond MPPT to overcome drawbacks of using a fixed step size. Simulation results show that this MPPT still presents a poor performance under low irradiance level. An adaptive InCond based on an enhanced step model and control strategy to track the MPP in an adaptive way has been proposed in [13]. Its main drawback is the difficulty of setting many initial parameters including the error permitted factor and precise direction control-scaling factors ( $\mathrm{N} 1$ and $\mathrm{N} 2)$. To this, the trial-error approach is the only path to tune these random parameters.

As discussed in [14], a well-designed FLC can offer a robust control of nonlinear systems. The conception phase of FLC for controlling nonlinear system does not require knowledge of the system's mathematical model. It integrates only the experts' experience into the design process to convert linguistic values into a control signal by means of three main stages: Fuzzification, inference and defuzzification. FLC has been hybridized with various Soft Computing (SC) techniques such as Genetic Algorithm (GA), Particle Swarm Optimization (PSO), Artificial Neural Network (ANN) and Ant Colony Optimization (FLC) to track the MPP. However, hybrid FLC-SC techniques have high complexity, as they need to process the three stages of FLC as well as to test a population of duty cycles or voltages by SC techniques. This makes the Hybrid FLC-SC MPPTs the most cumbersome and complex algorithms. To get rid of the abovementioned drawbacks and to improve the PV system efficiency, FLC has been hybridized with conventional MPPTs. An intelligent fuzzy discrete proportional-integral-derivative (FL-DPID) MPPT for battery charging control is proposed in [15] for enhancing battery life time and reducing power loss. The controller algorithm is based on regulating the power delivered to the battery by considering the transition response and the ripples in the output voltage and current. Nine fuzzy rules have been used to achieve better tracking 
performance compared to conventional $\mathrm{P} \& \mathrm{O}$ and InCond. To surmount the drawbacks of using a fixed step size HC methods, a hybrid FL-HC MPPT control technique is proposed in [16]. FL-HC MPPT varies the step size to improve the response time under fast variations of irradiance. However, oscillations around the MPP are the main limits of this MPPT. An amelioration of P\&O using FLC is presented in[17]. Low oscillations and high efficiency in tracking the MPP are achieved using the proposed strategy compared to conventional $\mathrm{P} \& \mathrm{O}$. However, the steady-state oscillations could not be completely eliminated. Moreover, Hybrid FL-P\&O MPPT suffers from slow response time, which causes significant power loss under fast variations of irradiance. Hybrid MPPTs based on InCondand FLC to track the MPP are proposed in [18-20]. The evaluation of these MPPTs depends on the type of membership functions, the number of fuzzy rules, and the tracking performance under different operating conditions. A hybrid InCond-FLC control technique is proposed in [18]. The ratio of derivative power and voltage, as well as the variation of this ratio are calculated and employed as the FLC inputs. The FLC output is passed through a PI control to regulate the switching converter duty cycle. The MPPT shows improved efficiency and reliability in tracking the MPP. However, using 49 fuzzy rules in addition to a PI controller increases the complexity of the control and slows its response time.

A combination of FL (9 fuzzy rule) and InCond has been experimentally tested in [19]. The algorithm may fail to achieve the accurate MPP for some operating conditions. The proposed MPPT in [20] employs FLC with 25 rules which are designed by considering the incremental conductance principle to generate the appropriate duty cycle for a buck-boost converter. No comparison with the existing MPPTs has been done to show the tracking efficiency of this MPPT. Thus, the major drawback of these methods is their development and applications for only standalone systems without considering the grid and ac loads. Accordingly, many researches centered on electricity transfer from the PV system to grid either by improving the inverter topologies or controllers' schemes. In low voltage applications, the use of a single-phase Hbridge circuit is adequate to coordinate the PV system to the utility grid. The inverter is capable of transferring DC measured voltage and current to desired AC waveforms respecting the stability margins and guarantee high power quality[21]. The control of this device might be guaranteed either by means of Direct Power Control (DPC) strategy which depends on the instantaneous active and reactive power control. Where the gates switch ON/OFF state is done utilizing a lookup table; or, through an indirect power method named Voltage Oriented Control (VOC). This technique depends on the change between stationary coordinate's $\alpha \beta$ and synchronous rotation coordinates $\mathrm{dq}$ and guarantees high dynamic and static performance via an inner current loop. Details of these techniques are done in [22-24]. The VOC is adopted to achieve the purpose of this paper and its details are elaborated in Section 3. The present paper proposes a hybrid MPPT technique that brings together the advantages of fuzzy and InCond for improving the tracking efficiency and minimizing losses when the power transferred to the AC-grid. PV system composed of PVG, DC-DC converter controlled by Hybrid FL-InCond MPPT, H-Bridge DC-AC inverter associated with the electrical grid through an L-filter and controlled by VOC strategy using the classical PI technique is developed and tested using MATLAB- Simulink platform.

The desired objectives to be achieved by the developed MPPT are:

- Improving the response time, this allows fast MPP tracking.

- Enhancing the power quality by decreasing ripples in the output current and voltage, hence, transferring maximum power to the grid.

- $\quad$ Achieve the MPP under irradiance variations.

- $\quad$ Maximizing the tracking efficiency.

The rest of this paper is organized as follows: firstly, the description of system and its parameters design are given in Section 2. The research method is explained in Section 3. The Simulation results and comparisons are presented in Section 4 and some conclusions and future work are given in Section 5.

\section{SYSTEM DESCRIPTION AND PARAMETERS DESIGN}

\subsection{System description}

Figure 1 shows the proposed grid-connected PV system. It includes a PVG connected to the dc-link inverter side through a DC-DC boost converter. The switching device of this latter is controlled by means of an improved fuzzy InCond MPPT. Then, the incorporation of the system to the grid is ensured through an $\mathrm{H}$-bridge circuit topology, which is adequate for low voltage applications. L-filter is inserted at the inverter output to eliminate the high-frequency current ripples. A VOC strategy is utilized to control the inverter switches states through the classical PI controller, and to generate the switching signals through Pulse Width Modulation technique (PWM). 


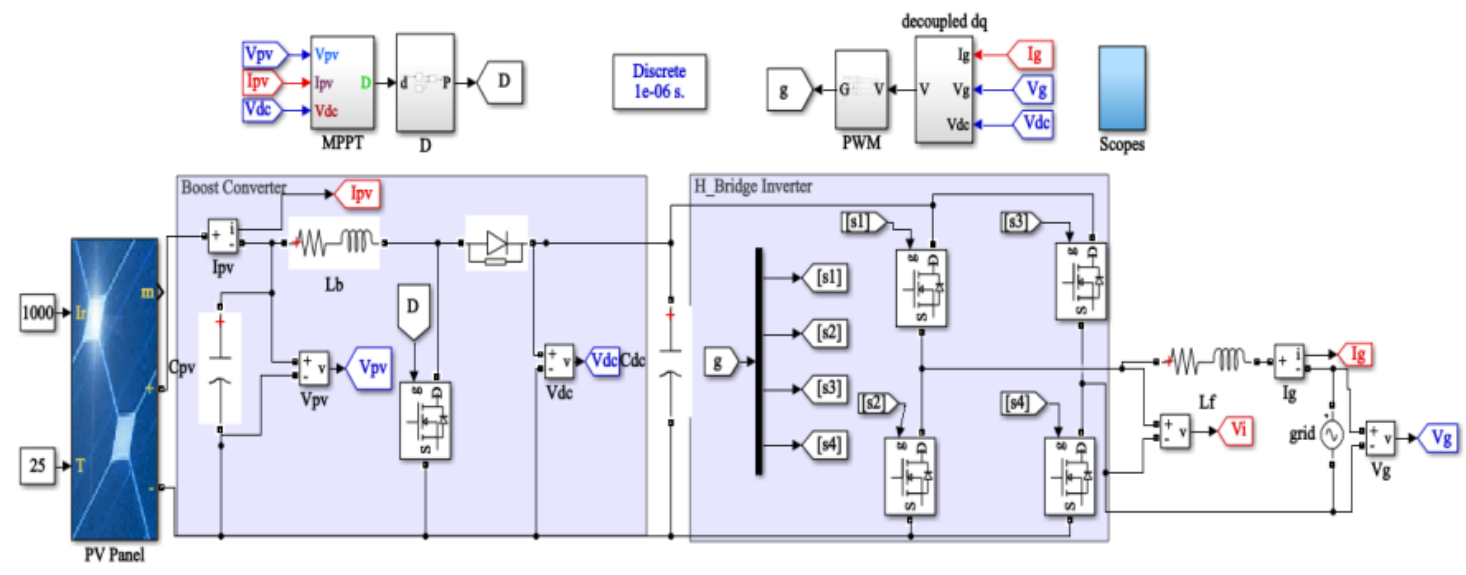

Figure 1. Grid connected PV system implementation in MATLAB/SIMULINK

\subsection{Boost converter parameters design}

To benefit from the PVG and extract its maximum available power, the design of the DC-DC stage is necessary. The converter contains an inductor, capacitor and a power switch (MOSFET or IGBT) controlled by an MPPT algorithm. According to the measured current and voltage at the PVG output side, the MPPT's control varies the duty cycle of the DC-DC converter to track the MPP, as well as to successfully limit the high current and voltage ripples for obtaining high-quality in the distributed power [18]. Consequently, the well-designed DC-DC boost converter is essential for achieving this goal. This can be done by determining the minimum values of $\mathrm{PV}$ output capacitor $\mathrm{C}_{\text {pvmin }}$, boost inductor $\mathrm{L}_{\mathrm{bmin}}$, and boost capacitor $\mathrm{C}_{\mathrm{bmin}}$ using the following relations $[15,25]$ :

$$
\begin{aligned}
& C_{p v \min }=\frac{\Delta I_{L}}{8 \Delta V_{p v} f} \\
& L_{b \min }=\frac{V_{p v} D}{2 \Delta I_{L} f} \\
& C_{b \min }=\frac{I_{L}(1-D) D}{8 \Delta V_{p v} f}
\end{aligned}
$$

where $\Delta \mathrm{I}_{\mathrm{L}}$ is the inductor ripple current and $\Delta \mathrm{V}_{\mathrm{pv}}$ is the voltage ripple across the PVG. D is the duty cycle. $\mathrm{I}_{\mathrm{L}}$ is the inductor current and $\mathrm{f}$ is the switching frequency.

\subsection{Inverter output L-filter design}

The inverter output inductor $\left(\mathrm{L}_{f}\right)$ minimizes the current ripples $\left(\Delta I_{\text {Lfrip }}\right)$ caused by the switching frequency $\left(f_{s w}\right)$ of the inverter. Frequently, a ripple of $20 \%$ is chosen in the inverter output current to select the $\mathrm{L}_{\text {finin }}, \Delta I_{\text {lfrip }}$ can be expressed as [26],[27] :

$$
\Delta I_{\text {lfrip } / \max }=\frac{V_{d c} T_{S}}{4 L_{f}}
$$

The minimum inverter inductor $\left(L_{f \min }\right)$ can be obtained as :

$$
L_{f \min }=\frac{V_{d c}}{4 f_{s w} \Delta I_{\text {ifrip }}}
$$

It is important to note that, the DC-DC converter and the H-bridge inverter are assumed to have the same switching frequency value $\left(f=f_{s w}\right)$ to offer a high dynamic response of the system.

\section{RESEARCH METHOD}

The proposed grid connected PV system controllers are developed within this section. The proposed FL-InCondis explained in sub-section (a) and schematized in flowchart of Figure 2. The VOC SIMULINK scheme is given by sub-section (b) and detailed as well. 


\subsection{Proposed FL-InCond MPPT}

In order to maximize power from the PVG and enhancing its efficiency, the design of an appropriate MPPT is necessary. Accordingly, an advanced hybrid FL-InCond MPPT is proposed by combining FL and InCond algorithms. The flowchart of the proposed algorithm is illustrated in Figure 2. At first, the algorithm acquires the PV voltage and current $\left(\mathrm{V}_{\mathrm{pv}}\right.$ and $\mathrm{I}_{\mathrm{pv}}$, respectively), as well as the load voltage $\left(\mathrm{V}_{\mathrm{dc}}\right)$ in order to calculate $\alpha_{\max }$ using the (8). $\alpha_{\max }$ is employed as a scaling factor to the FLC input. It represents the ratio between the maximum load voltage $\left(\mathrm{V}_{\mathrm{dcmax}}\right)$ and maximum $\mathrm{PV}$ voltage $\left(\mathrm{V}_{\mathrm{mpp}}\right)$. The voltage transfer function of the boost converter is written as [4],[19]:

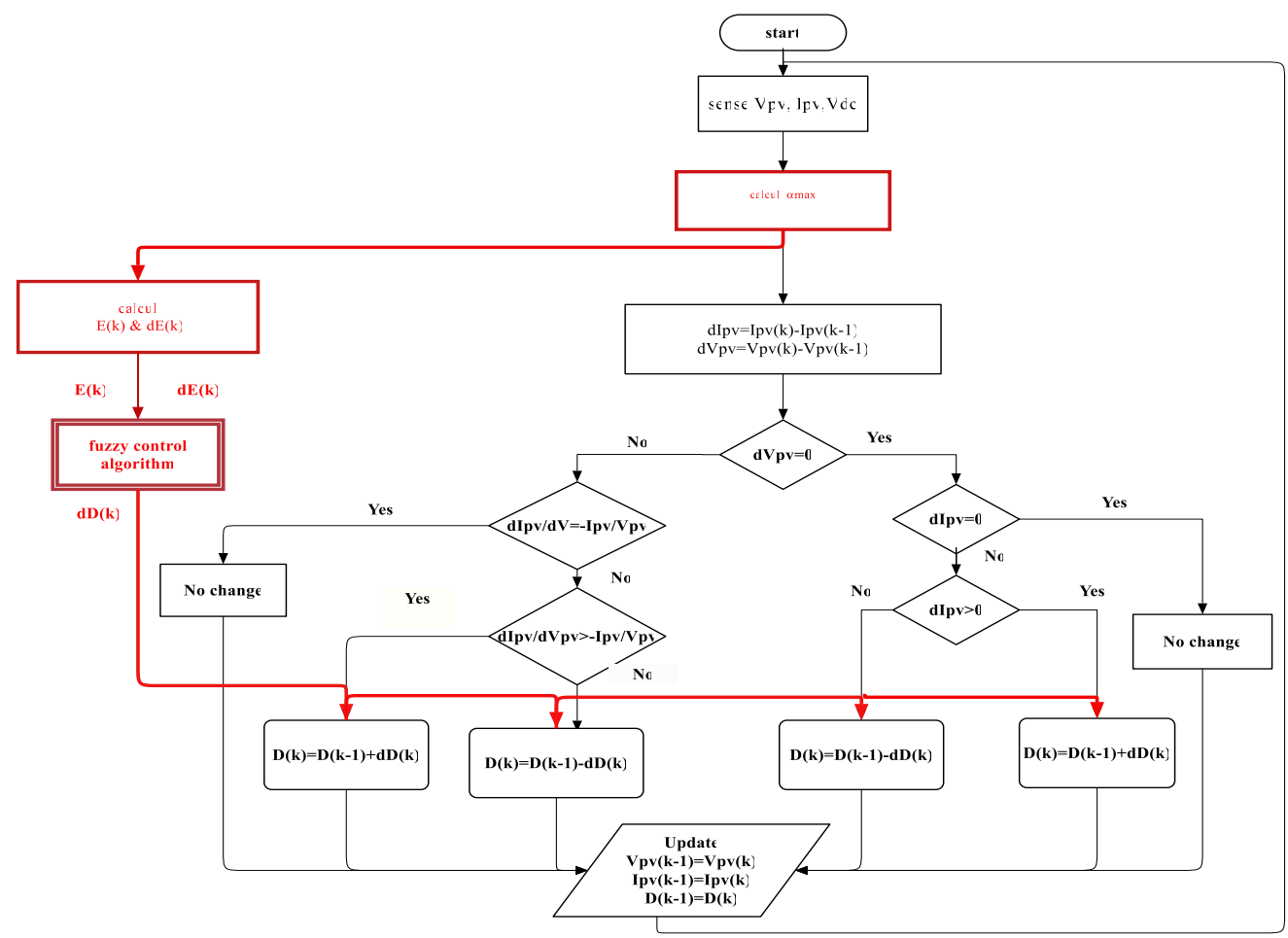

Figure 2. The proposed MPPT algorithm flowchart

$$
\frac{V_{d c}}{V_{p v}}=\frac{I_{p v}}{I_{d c}}=\frac{1}{1-D}=\alpha
$$

where $\mathrm{V}_{\mathrm{pv}}, \mathrm{V}_{\mathrm{dc}}$ are the PV voltage and load voltage, respectively and $\mathrm{I}_{\mathrm{pv}}, \mathrm{I}_{\mathrm{dc}}$ are the PV current and load current, respectively. $\mathrm{D}_{\max }$ is selected by employing the maximum $\mathrm{PV}$ Voltage $\left(\mathrm{V}_{\mathrm{mpp}}\right)$, maximum power $\left(\mathrm{P}_{\mathrm{mpp}}\right)$ and the resistive load value $\left(R_{\text {load }}\right)$ according to the following relation

$$
D_{\text {max }}=1-\frac{V_{\text {mpp }}}{\sqrt{P_{\text {mpp }} * R_{\text {load }}}}
$$

The value of $\alpha_{\max }$ used in the proposed method is computed by considering (6) and (7) as follows

$$
\alpha_{\max }=\frac{1}{1-D_{\max }}
$$

By obtaining $\alpha_{\max }$, the ratio of the output and input voltage of the boost converter can be expressed using an adaptive $\alpha_{\max }$ value as:

$$
\mathrm{E}(\mathrm{k})=\frac{\mathrm{dV}_{\mathrm{dc}}(\mathrm{k})}{\alpha_{\max } \times \mathrm{dV}_{\mathrm{pv}}(\mathrm{k})}
$$

The variation in the error $\mathrm{E}(\mathrm{k})$ can be expressed as 


$$
\mathrm{dE}(\mathrm{k})=\mathrm{E}(\mathrm{k})-\mathrm{E}(\mathrm{k}-1)
$$

(9) and (10) are used as inputs of the fuzzy system. When the values of $\mathrm{E}(\mathrm{k})$ and $d E(k)$ are small (i.e the instantaneous power is approaching the MPP), a small value of $d D$ should be selected by the FLC. However, in the in the case where $\mathrm{E}(\mathrm{k})$ and $d E(k)$ are large, a large value of $d D$ should be selected. $\mathrm{E}(\mathrm{k})$ and $d E(k)$ are the inputs of the FLC and $d D$ is the output. The input variables are divided into five membership functions: NB, NS, ZE, PS and PB. Therefore, the resulting numbers of rules are 25 processed by Mamdani fuzzy inference system (with max-min). Table 1 recapitulates the fuzzy rules.

\begin{tabular}{cccccc}
\multicolumn{6}{c}{ Table 1. Fuzzy rules } \\
\hline E & NB & NS & ZE & PS & PB \\
dE & & & & & \\
\hline ZE & NB & NB & NM & NS & ZE \\
NS & NB & NM & NS & ZE & PS \\
ZE & NM & NS & ZE & PS & PM \\
PS & NS & ZE & PS & PM & PB \\
PB & ZE & PS & PM & PB & PB \\
\hline
\end{tabular}

The diffuzification stage uses seven membership functions (NB: negative big, NS: negative small, NM: negative medium, ZE: zero, PS: positive small, PM: positive medium PB: positive big) alongside the center of gravity technique for calculating the appropriate step size $d D$,

$$
d D=\frac{\sum_{i}^{n} \mu\left(D_{i}\right) D_{i}}{\sum_{i}^{n} \mu\left(D_{i}\right)}
$$

where $d D$ is the control signal provided by the FLC and $\mathrm{D}_{\mathrm{i}}$ are the center of the max-min composition in the output membership functions. Shape of the FLC membership functions are shown in Figure 3.
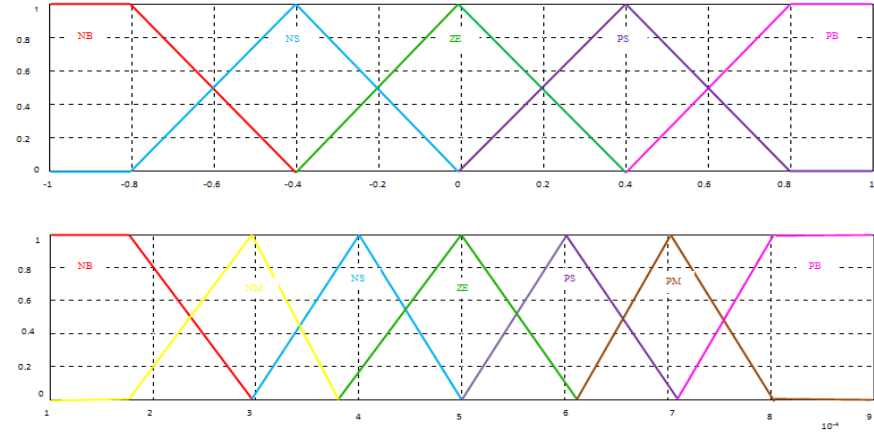

Figure 3. Membership functions: (a) Input of FLC: E and dE (b) Output of FLC: dD

The duty cycle is incremented or decremented by $d D$ through carrying out the FLC rules. An accurate duty cycle D is obtained by combining FLC and InCond MPPT. Variations of the PV voltage $\left(\mathrm{dV}_{\mathrm{pv}}\right)$ and the PV current $\left(\mathrm{dI}_{\mathrm{pv}}\right)$ are calculated as follows

$$
\begin{aligned}
& d V_{p v}(k)=V_{p v}(k)-V_{p v}(k-1) \\
& d I_{p v}(k)=I_{p v}(k)-I_{p v}(k-1)
\end{aligned}
$$

- If $\mathrm{dV}_{\mathrm{pv}}$ is equal to zero, the variation of PV current $\left(\mathrm{dI}_{\mathrm{pv}}\right)$ is calculated. If $\mathrm{dI}_{\mathrm{pv}}$ is equal zero, it means that the MPP is achieved and the old value of the duty cycle $\mathrm{D}(\mathrm{k}-1)$ is kept. If $\mathrm{dI}_{\mathrm{pv}}$ is higher or lower than zero, the duty cycle $\mathrm{D}$ is incremented or decremented, respectively, by a step size $d D$. 
- If $\mathrm{dV}_{\mathrm{pv}}$ is different from zero, the instantaneous conductance $\left(\frac{d I_{p v}(k)}{d V_{p v}(k)}\right)$ and the incremental conductance $\left(\frac{I_{p v}(k)}{V_{p v}(k)}\right)$ are calculated and compared. If no change is detected, $\mathrm{D}(\mathrm{k}-1)$ is kept. However, if $\left(\frac{d I_{p v}(k)}{d V_{p v}(k)}\right)>-$ $\left(\frac{I_{p v}(k)}{V_{p v}(k)}\right)$ the duty cycle is incremented by a step size $(\mathrm{dD})$.Otherwise, the duty cycle is decremented.

\subsection{Inverter Control}

The voltage oriented control or VOC is an indirect strategy of controlling the active and reactive power during the incorporation of micro-grids to the electrical grid. It aims at orienting the current vector regarding the line voltage vector through active and reactive current control[23]. The principal function of this method is to minimize the error between Id ,Iq (direct and quadrature parts of the measured grid current and transformed using Park Transformation) and their reference values Id-ref, Iqrefrespectively. The value of Idref is obtained through an outer PI controller loop which also stabilizes the inverter DC-side voltage. Iqref is kept equal to zero (Iqref=0) to compensate any injected reactive power to the system and guarantee unit power factor. These errors are fed to PI controllers in an Inner Current Control loops capable of regulating the output $\mathrm{H}$-bridge current. Finally, $\mathrm{Vdand} \mathrm{Vq}$ voltages are generated and converted to modulating signals employed by the PWM inverter pulse generator. The advantage of this method are the high ability of minimizing the THD and ensuring satisfactory dynamic and static performances [24]. The controller described above is depicted in Figure 4, while the PI control transfer function is done in (14), whereinKp and $\mathrm{Ki}$ are the proportional and integral gains respectively.

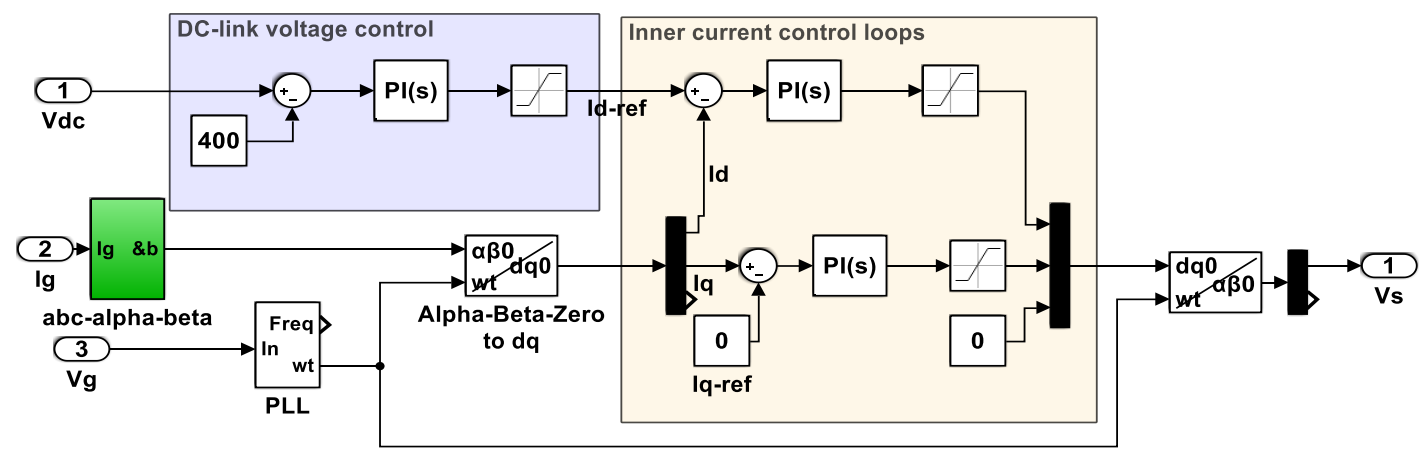

Figure 4. VOC H-bridge inverter control

$$
G_{P I}(s)=k_{P}+k_{i} s
$$

The derived transfers function of the d-q currents loops are done as:

$\frac{I_{d}(s)}{I_{\text {dref }}(s)}=\frac{I_{q}(s)}{I_{\text {qref }}(s)}=\frac{k_{P}+k_{i} s}{L_{f} s^{2}+\left(k_{P}+r\right) s+k_{i}}$

where $r$ is the inverter output inductor's resistance .

The standard second order transfer function is defined as

$G(\mathrm{~s})=\frac{\mathrm{k}_{\mathrm{p}} \omega_{\mathrm{n}}^{2}}{\mathrm{~s}^{2}+2 \zeta \omega_{\mathrm{n}}^{2} \mathrm{~s}+\omega_{\mathrm{n}}^{2}}$

where $\omega_{n}=\sqrt{\frac{k_{i}}{L_{f}}}, \zeta=\frac{k_{P}+r}{2 \sqrt{k_{i} L_{f}}}$

$\omega_{\mathrm{n}}$ and $\zeta$ are natural frequency and damping ratio of the system respectively.

Comparing (15) and (16), we get the current control gains as

$$
\mathrm{k}_{\mathrm{P}}=2^{\zeta} \omega_{\mathrm{n}} \mathrm{L}_{\mathrm{f}}-\mathrm{r}
$$




$$
\mathrm{k}_{\mathrm{i}}=\mathrm{L}_{\mathrm{f}} \omega_{\mathrm{n}}
$$

Obviously, the design of gains defined by the equations must guarantee the stability margins and the dynamic performance.

\section{RESULTS AND ANALYSIS}

This section is devoted to evaluating the performance of the proposed MPPT. To this end, analyses of many performance indices at different operating conditions, as well as comparisons with conventional $\mathrm{P} \& \mathrm{O}$ and InCond for grid-connected mode are carried out. Firstly, the proposed MPPT is evaluated under standard test condition (STC; $1 \mathrm{~kW} / \mathrm{m}^{2}$ at $25^{\circ} \mathrm{C}$ ). Secondly, tests under fast varying irradiance conditions are carried out. Finally, a comparison to conventional $\mathrm{P} \& \mathrm{O}$, InCond is performed to validate the proposed technique. The Matlab-Simulink software package has been employed for implementing the PV system, as shown in Figure 1. The simulation parameters are presented in Table 2.

Table 2. The implemented system Parameter settings

\begin{tabular}{llll}
\hline & Symbol & Parameter & Value \\
\hline PV & PMPP & Maximum power & $334.905 \mathrm{~W}$ \\
Module & VMPP & Voltage at Pmax & $41.5 \mathrm{~V}$ \\
& IMPP & Current at Pmax & $8.07 \mathrm{~A}$ \\
DC-DC & CPV & PV capacitor & $110 \square \mathrm{f}$ \\
Converter & Lb & Boost inductance & $3 \mathrm{mH}$ \\
& Cdc & DC-Link Capacitor & $3300 \square \mathrm{f}$ \\
& fsw & Switching frequency & $20 \mathrm{KHz}$ \\
AC side & Lf & Filter inductor & $3 \mathrm{mH}$ \\
& rf & Filer resistor & $0.01 \mathrm{ohm}$ \\
& Vg & Grid voltage & $220 \mathrm{~V}$ \\
& fsw & Switching frequency & $20 \mathrm{KHz}$ \\
\hline
\end{tabular}

\subsection{Test under $\mathrm{STC}\left(1 \mathrm{~kW} / \mathrm{m}^{2}\right.$ at $\left.25^{\circ} \mathrm{C}\right)$}

Figure 5 shows the measured current, voltage and power $\mathrm{I}_{\mathrm{pv}}, \mathrm{V}_{\mathrm{pv}}$ and $\mathrm{P}_{\mathrm{pv}}$, respectively under STC. Short transient time has been obtained by the proposed MPPT, which is around $30 \mathrm{~ms}$. Throughout this operation condition, the instantaneous PV power, $\mathrm{P}_{\mathrm{pv}}$ has been maintained at $334 \mathrm{~W}$, which is the desired maximum power that must be obtained at STC (Figure 5.c).As can be seen from Figure 5.a. and b, the instantaneous voltage $\left(\mathrm{V}_{\mathrm{pv}}\right)$ and current $\left(\mathrm{I}_{\mathrm{pv}}\right)$ are around their maximum values, which are $41.5 \mathrm{~V}, 8.07 \mathrm{~A}$, respectively. Figure 6.(a) shows the voltage at the inverter DC-side and its reference $\left(\mathrm{V}_{\mathrm{dc}}\right.$ and $\left.\mathrm{V}_{\mathrm{dc} \_ \text {ref }}\right)$ under STC. It can be noted that the dc voltage has been boosted to the desired level, which is $400 \mathrm{~V}$. Therefore, the proposed MPPT is capable of regulating the voltage and minimizing loss. Hence, the inverter output current waveform is purely sinusoidal and also well synchronized with the grid voltage as shown in the Figure 6. (b). this permits the transfer of maximum power to the grid and ensures unit power factor. Additionally, the analysis of the THD using MATLAB/SIMULINK POWERGUI for both voltage and current gives values of $0.02 \%$ and $1.16 \%$ respectively which conforms to that given by IEEE 519- standard. The active power exported by the inverter is equal to DC-power while the reactive power rests equal to zero.
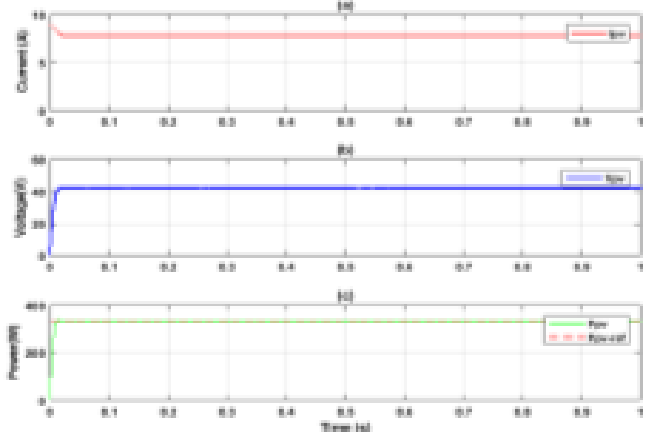

Figure 5 .PV output(a) current, (b)voltage and(c)Power at $\mathrm{STC}\left(25^{\circ} \mathrm{C} \& 1 \mathrm{~kW} / \mathrm{m}^{2}\right)$
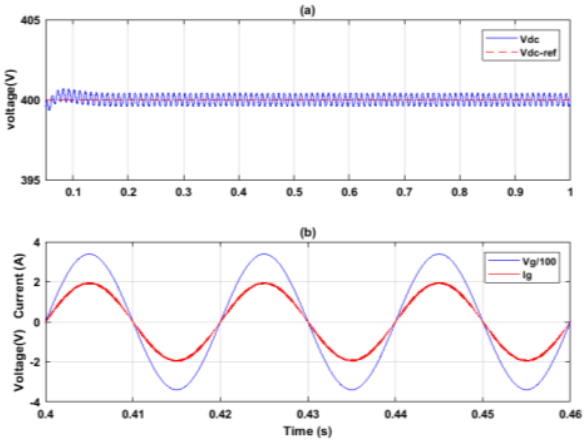

Figure 6. (a) DC-link Voltage, (b) PCC Voltage and current 


\subsection{Test under varying irradiance}

Environmental conditions are time varying. Therefore, checking the ability of the proposed MPPT in tracking the MPP under fast variations of irradiance is necessary. This has been accomplished by varying the irradiance many times within a few seconds. Four levels are considered in this test, which are $1 \mathrm{~kW} / \mathrm{m}^{2}, 0 \mathrm{~W} / \mathrm{m}^{2}, 0.5 \mathrm{~kW} / \mathrm{m}^{2}, 0.9 \mathrm{~kW} / \mathrm{m}^{2}$. MPPs, corresponding to the aforementioned irradiance levels are: $334.53 \mathrm{~W}, 0 \mathrm{~W}, 166.2 \mathrm{~W}$ and $301.71 \mathrm{~W}$, respectively. As can be seen from Figure 7, thanks to the proposed MPPT, the output PV voltage $\left(\mathrm{V}_{\mathrm{pv}}\right)$ and current $\left(\mathrm{I}_{\mathrm{pv}}\right)$ are kept around their maximum values $\mathrm{V}_{\mathrm{mpp}}$ and $\mathrm{I}_{\mathrm{mpp}}$, respectively. This means that the instantaneous power of the PVG achieves the MPP (the red dashed line) for each level of irradiance (Figure 7c). High performance and stability are shown in the DC-link voltage which is kept around its reference $(400 \mathrm{~V})$ under irradiance variations applied to the PV system Figure 8. Furthermore, the inverter output current keeps a sinusoidal waveform with variable amplitude Figure 9 staying in phase with the grid voltage. Small THD values are shown in both current and voltage and the FFT analysis gives values of $1.16 \%$ and $0.01 \%$ respectively.

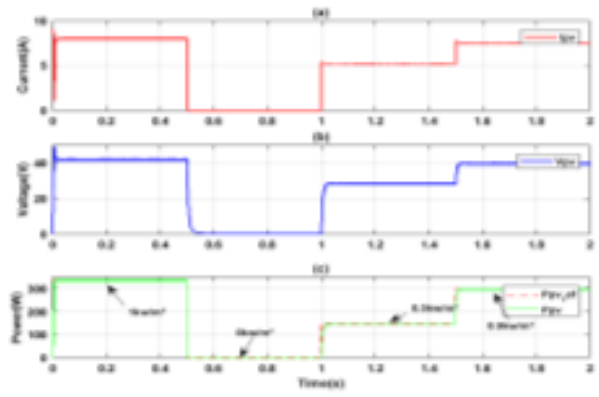

Figure 7. PV output (a), current (b) voltage and (c) Power under fast varying irradiance condition

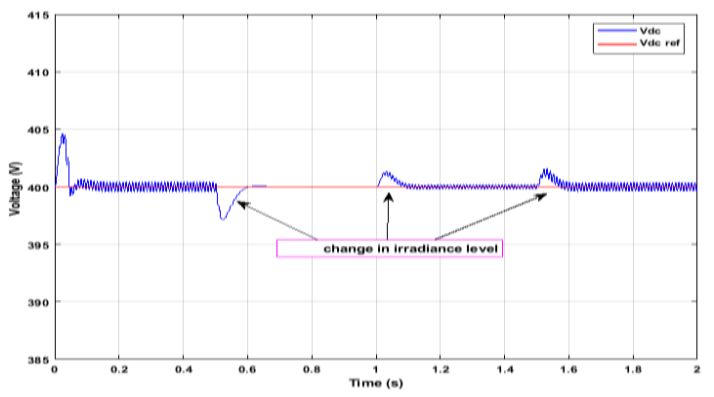

Figure 8.DC-link voltage $\left(\mathrm{V}_{\mathrm{dc}}\right)$ under fast variations of irradiance

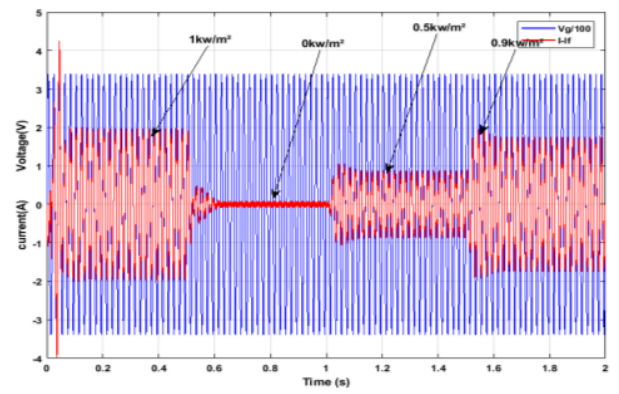

Figure 9. PCC Voltage and current under fast variations of irradiance

\subsection{Comparison with conventional P\&O and InCond MPPTs}

In this sub-section, further assessments of performance under fast variations of irradiance and temperature are carried out. To this end, two well-known MPPT methods, namely conventional P\&O [13] and InCond [28]are employed in the present comparison. Results showing waveforms of the PV output power obtained by the proposed MPPT, P\&O and In-Cond are depicted in Figure 10. Table 3 represents a comparison in terms of convergence time, steady-state error, average power at $1 \mathrm{~kW} / \mathrm{m}^{2}$, tracking efficiency, grid current THD and the error between $\mathrm{P}_{\mathrm{PV}}$ and $\mathrm{P}_{\mathrm{g}}$ between the proposed MPPT, P\&O and InCond. As can be seen from Table 3, the numerical values of convergence time demonstrate the superior tracking performance of the proposed MPPT $(20 \mathrm{~ms})$. Whereas, P\&O and InCond take around 40.2ms and 38.9ms, respectively, to reach the MPP. P\&O presents power ripple around the MPP and consequently, lower efficiency in tracking the MPP (around 97.04\%), Compared to $98.3 \%$ for InCond. While the proposed method presents a high tracking efficiency of $99.07 \%$.The power transmitted from the PVG to the grid under the control of the proposed MPPT has a low power loss (around $4 \mathrm{~W}$ ) due to the control of both the PV voltage $\left(\mathrm{V}_{\mathrm{pv}}\right)$ and the inverter dc-side voltage $\left(\mathrm{V}_{\mathrm{dc}}\right)$, while the power loss using $\mathrm{P} \& \mathrm{O}$ and InCond is high ( 
$6.57 \mathrm{~W}$ and $8.42 \mathrm{~W}$ respectively ).This leads to a low THD in current delivered at PCC $1.16 \%$ compared to $1.43 \%$ and $2.03 \%$ using InCond and $\mathrm{P} \& \mathrm{O}$, respectively.

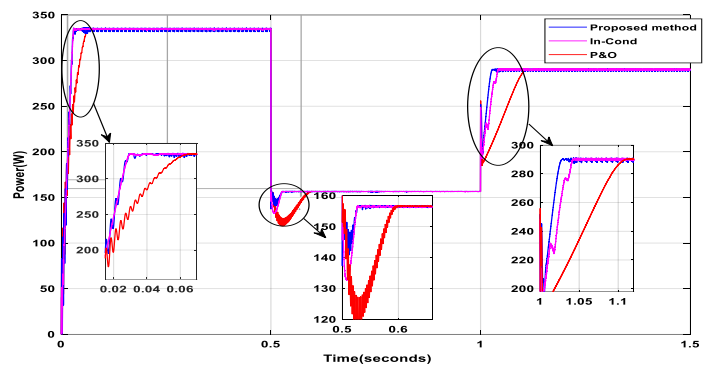

Figure 10. PV power extracted by P\&O, InCond and the proposed MPPT under fast variations of irradiance

Table 3. P\&O, InCond and the proposed MPPT Performances

\begin{tabular}{lllllll}
\hline MPPT Methods & $\operatorname{Tr}(\mathrm{ms})$ & $\begin{array}{c}\text { Steady-state } \\
\text { error }(\mathrm{W})\end{array}$ & $\begin{array}{c}\text { Average power at } \\
1000 \mathrm{w} / \mathrm{m}^{2}\end{array}$ & Efficiency $(\%)$ & $\begin{array}{c}\text { Grid current THD } \\
(\%)\end{array}$ & $\left|P_{P V}-P_{g}\right|(\mathrm{W})$ \\
\hline P\&O & 40.2 & 9.9050 & $325 \mathrm{~W}$ & 97.04 & 2.03 & 8.42 \\
InCond & 38.9 & 5.6924 & $329.2116 \mathrm{~W}$ & 98.3 & 1.43 & 6.57 \\
$\begin{array}{l}\text { Proposed } \\
\text { method }\end{array}$ & 20 & 3.1106 & $331.7904 \mathrm{~W}$ & 99.07 & 1.16 & 4.31 \\
\hline
\end{tabular}

\section{CONCLUSION}

In this paper an improvement of the PV system efficiency and of the quality of the power delivered through a newly proposed FL-InCond MPPT that uses an automatic tuning-controller of step size, investigating the features of both InCond and FL controllers. In fact, the improved FL-InCond method allows the minimization of power loss between the PVG side and grid side $(4.31 \mathrm{w})$ compared to $6.57 \mathrm{~W}$ and $8.42 \mathrm{~W}$ using InCond and $\mathrm{P} \& \mathrm{O}$ respectively, offers better dynamic and steady-state performances, minimizes distortions in current through the THD improvement. So, high power quality, efficiency, and reliability are obtained compared to existing MPPT techniques. Moreover, results under standard and dynamic conditions verify the feasibility, effectiveness and accuracy of the planned control, where a fast convergence speed is achieved using the proposed method compared to InCond and $\mathrm{P} \& \mathrm{O}$ with only $20 \mathrm{~ms}$, compared to $38.9 \mathrm{~ms}$ and $40.2 \mathrm{~s}$, respectively. In our future research, we intend to experimentally validation of the proposed method, integrate it to large scale and hybrid grid-connected micro-grid systems including linear and non-linear loads by keeping its efficiency and power quality continuously at maximum level.

\section{REFERENCES}

[1] REN21 MEMBERS, "RENEWABLES 2019 GLOBAL STATUS REPORT,” 2019.

[2] K. Kachhiya, M. Lokhande, and M. Patel, "MATLAB/Simulink model of solar PV module and MPPT algorithm," in National Conference on Recent Trends in Engineering \& Technology, 2011.

[3] R. Boukenoui, R. Bouhedir, A. Mellit, and S. Saglam, "Experimental assessment of Poly C-Si, CIGS and CdTe Photovoltaic technologies under real working conditions," in 2019 International Conference on Wireless Technologies, Embedded and Intelligent Systems (WITS), pp. 1-4, 2019.

[4] M. A. Enany, M. A. Farahat, and A. Nasr, "Modeling and evaluation of main maximum power point tracking algorithms for photovoltaics systems," Renewable and Sustainable Energy Reviews, vol. 58, pp. 1578-1586, 2016.

[5] R. Boukenoui, H. Salhi, R. Bradai, and A. Mellit, "A new intelligent MPPT method for stand-alone photovoltaic systems operating under fast transient variations of shading patterns," Sol. Energy, vol. 124, pp. 124-142, Feb. 2016.

[6] M. A. Enany, M. A. Farahat, and A. Nasr, "Modeling and evaluation of main maximum power point tracking algorithms for photovoltaics systems," Renewable and Sustainable Energy Reviews, vol. 58. Elsevier Ltd, pp. 1578-1586, 01-May-2016.

[7] M. A. Abdourraziq and M. Maaroufi, "Experimental Verification of the Main MPPT Techniques for Photovoltaic System", International Journal of Power Electronics and Drive Systems (IJPEDS), Vol. 8, No. 1, pp. 384 - 391, March 2017.

[8] Z. Salam, J. Ahmed, and B. S. Merugu, "The application of soft computing methods for MPPT of PV system: A technological and status review," Applied Energy, vol. 107, pp. 135-148, 2013. 
[9] B. Boukezata, A. Chaoui, J. P. Gaubert, and M. Hachemi, "An improved fuzzy logic control MPPT based P\&O method to solve fast irradiation change problem," J. Renew. Sustain. Energy, vol. 8, no. 4, Jul. 2016.

[10] R. Boukenoui, M. Ghanes, J. P. Barbot, R. Bradai, A. Mellit, and H. Salhi, "Experimental assessment of Maximum Power Point Tracking methods for photovoltaic systems," Energy, vol. 132, pp. 324-340, 2017.

[11] M. S. Hassan, S. N. Mughal, R. K. Jarial, and Y. R. Sood, "A Comparative Analysis of Different Maximum Power Point Tracking Algorithms of Solar Photovoltaic System," in Lecture Notes in Electrical Engineering, vol. 553, pp. 217-229, 2019.

[12] R. Ranjan Sahoo and M. Singh, "Analysis of Variable Step Incremental Conductance MPPT Technique for PV System," in J.EEE, vol. 11, no. 2, pp. 41-48, 2016.

[13] C. Li, Y. Chen, D. Zhou, J. Liu, and J. Zeng, "A high-performance adaptive incremental conductance MPPT algorithm for photovoltaic systems," Energies, vol. 9, no. 4, Apr. 2016.

[14] Y. Zou, F. Yan, X. Wang, and J. Zhang, "An Efficient Fuzzy Logic Control Algorithm for Photovoltaic Maximum Power Point Tracking under Partial Shading Condition,” J. Franklin Inst., Sep. 2019.

[15] P. K. Pathak and A. K. Yadav, "Design of battery charging circuit through intelligent MPPT using SPV system," Sol. Energy, pp. 79-89, Jan. 2019.

[16] B. N. Alajmi, K. H. Ahmed, S. J. Finney, and B. W. Williams, "Fuzzy-logic-control approach of a modified hillclimbing method for maximum power point in microgrid standalone photovoltaic system," IEEE Trans. Power Electron., vol. 26, no. 4, pp. 1022-1030, 2011.

[17] K. Nebti and F. Debbabi, "Amelioration of MPPT P\&O Using Fuzzy-Logic Technique for PV Pumping," in Lecture Notes in Networks and Systems, vol. 62, Springer, pp. 400-410, 2019.

[18] N. I. Cazac Vadim, "Photovoltaic System Modeling With Fuzzy Logic Based Incrimental Conductance Tracking Algorithm," in The 7th International Conference on Modern Power Systems ,2017.

[19] T. Radjai, L. Rahmani, S. Mekhilef, and J. P. Gaubert, "Implementation of a modified incremental conductance MPPT algorithm with direct control based on a fuzzy duty cycle change estimator using dSPACE," Sol. Energy, vol. 110, pp. 325-337, Dec. 2014.

[20] T. Ratna Ika Putri1, Sapto Wibowo2, M. Rifa'i3, "Fuzzy Incremental Conductance for Maximum Power Point Tracking in Photovoltaic System," Int. J. Eng. Sci. Innov. Technol. , vol. Vol. 3, no. 6, 2014.

[21] M. Shayestegan, "Overview of grid-connected two-stage transformer-less inverter design," Journal of Modern Power Systems and Clean Energy, vol. 6, no. 4. Springer Heidelberg, pp. 642-655, 01-Jul-2018.

[22] M. Monfared, M. Sanatkar, and S. Golestan, "Direct active and reactive power control of single-phase grid-tie converters," IET Power Electron., vol. 5, no. 8, pp. 1544-1550, Sep. 2012.

[23] Y. Yang, C. Q. Qi, J. Suo, and F. W. Cao, "Singe-phase grid-connected inverter based on voltage-oriented control in photovoltaic generation systems," in Advanced Materials Research, vol. 765-767, pp. 2498-2502,2013.

[24] M. Ebrahimi, S. A. Khajehoddin, and M. Karimi-Ghartemani, "Fast and Robust Single-Phase DQ Current Controller for Smart Inverter Applications," IEEE Trans. Power Electron., vol. 31, no. 5, pp. 3968-3976, May 2016.

[25] Y. Amara, R. Boukenoui, R. Bradai, and H. Salhi, "Design and Control of Two-Stage Standalone Photovoltaic Generation System," in 2018 International Conference on Communications and Electrical Engineering (ICCEE), pp. 1-5 , 2018.

[26] M. Abdur Razzak, et al.,, "Design of a Grid-connected Photovoltaic Inverter with Maximum Power Point Tracking using Perturb and Observe Technique," International Journal of Power Electronics and Drive System (IJPEDS), Vol. 7, No. 4, pp. 1212 1220, December 2016,

[27] Z. Rasin, and A. Jidin, " Design and Development of Grid-connected Quasi-Z-Source PV Inverter," International Journal of Power Electronics and Drive Systems (IJPEDS), vol. 9, no. 4, pp. 1989-2005,2018.

[28] M. A. Abdourraziq and M. Maaroufi, "Experimental Verification of the Main MPPT Techniques for Photovoltaic System", International Journal of Power Electronics and Drive Systems (IJPEDS), Vol. 8, No. 1, pp. 384 - 391, March 2017. 